\title{
BMJ Global Health Everyday resilience in district health systems: emerging insights from the front lines in Kenya and South Africa
}

\author{
Lucy Gilson, ${ }^{1,2}$ Edwine Barasa, ${ }^{3}$ Nonhlanhla Nxumalo, ${ }^{4}$ Susan Cleary, ${ }^{1}$ \\ Jane Goudge, ${ }^{4}$ Sassy Molyneux, ${ }^{3,5}$ Benjamin Tsofa, ${ }^{3}$ Uta Lehmann ${ }^{6}$
}

To cite: Gilson L, Barasa E, Nxumalo N, et al. Everyday resilience in district health systems: emerging insights from the front lines in Kenya and South Africa. BMJ Glob Health 2017;2:e000224. doi:10.1136/ bmjgh-2016-000224

Received 26 0ctober 2016 Revised 25 February 2017 Accepted 28 March 2017

\section{(a) CrossMark}

- Additional material is published online only. To view please visit the journal online (http://dx.doi.org/10.1136/ bmjgh-2016-000224).

${ }^{1}$ School of Public Health and Family Medicine, University of Cape Town, Cape Town, South Africa

${ }^{2}$ Department of Global Health and Development, London School of Hygiene and Tropical Medicine, London, UK ${ }^{3}$ Center for Geographical Medicine, KEMRI-Wellcome Trust Programme, Nairobi, Kenya

${ }^{4}$ Centre for Health Policy, University of the Witwatersrand, Johannesburg, South Africa ${ }^{5}$ Centre for Tropical Medicine and Global Health, Nuffield Department of Medicine, University of Oxford, Oxford, UK ${ }^{6}$ School of Public Health, University of the Western Cape, Cape Town, South Africa

Correspondence to

Lucy Gilson;

lucy.gilson@uct.ac.za

\section{ABSTRACT}

Recent global crises have brought into sharp relief the absolute necessity of resilient health systems that can recognise and react to societal crises. While such crises focus the global mind, the real work lies, however, in being resilient in the face of routine, multiple challenges. But what are these challenges and what is the work of nurturing everyday resilience in health systems? This paper considers these questions, drawing on long-term, primarily qualitative research conducted in three different district health system settings in Kenya and South Africa, and adopting principles from case study research methodology and meta-synthesis in its analytic approach. The paper presents evidence of the instability and daily disruptions managed at the front lines of the district health system. These include patient complaints, unpredictable staff, compliance demands, organisational instability linked to decentralisation processes and frequently changing, and sometimes unclear, policy imperatives. The paper also identifies managerial responses to these challenges and assesses whether or not they indicate everyday resilience, using two conceptual lenses. From this analysis, we suggest that such resilience seems to arise from the leadership offered by multiple managers, through a combination of strategies that become embedded in relationships and managerial routines, drawing on wider organisational capacities and resources. While stable governance structures and adequate resources do influence everyday resilience, they are not enough to sustain it. Instead, it appears important to nurture the power of leaders across every system to reframe challenges, strengthen their routine practices in ways that encourage mindful staff engagement, and develop social networks within and outside organisations. Further research can build on these insights to deepen understanding.

\section{INTRODUCTION}

The West African Ebola crisis of 2014-2015 sharply highlighted the importance of resilient health systems that can recognise and respond to health crises. ${ }^{1}$ However, the concept of resilience has a long history and wide use outside the health sector. In organisational theory, it is specifically applied 'to provide insight into how organisations continually achieve desirable outcomes amid adversity, strain, and significant barriers to adaptation and development'. ${ }^{2}$ Rather than the acute, external shocks emphasised in current international health policy discussions, this literature highlights the common organisational challenges of rapid change, poor leadership and client demands. ${ }^{12}$ Resilience is, then, defined as 'the maintenance of positive adjustment under challenging conditions such that the organisation emerges from those conditions strengthened and more resourceful'?

Building on these ideas, the aim of this paper is to explore the need for, and nature of, everyday resilience within health systems, considering the routine challenges they face and the strategies employed to address them. We focus specifically on the district as it is the foundation of every strong health system, necessary to bring about the reorientation to primary healthcare (PHC) long acknowledged to be vital in pursuit of population health needs and equity goals. ${ }^{4}$ Resilience at this level is particularly important given diverse and changing health and social needs, and its interface with other sectors and community systems. ${ }^{5}$ Yet very little work has so far considered everyday resilience in district health systems: Lembani et at provide a rare example.

The evidence presented in the paper is drawn from three long-term collaborations between research teams and health system actors in specific districts in Kenya and South Africa. We did not set out to investigate resilience in these settings, but, more broadly, to understand these district health systems by seeing their experience through the eyes of the managers and staff working at the front lines of healthcare delivery and community engagement. Drawing on these experiences, this paper presents evidence to illuminate both the challenging conditions faced in districts and the system responses to those challenges. We then review the responses using two theoretical 


\section{Key questions}

\section{What is already known about this topic?}

- Resilience has become the new buzz word in international health policy debates as a way of thinking about how health systems cope with significant external shocks, like the Ebola crisis of 2014-2015.

- There is limited acknowledgement of the routine challenges that also demand resilience, and there is very little empirical evidence about how to nurture resilience within health systems.

- Insufficient attention is paid to organisational literature, that understands resilience to provide insights on how organisations continually achieve desirable outcomes in the face of multiple, routine challenges.

What are the new findings?

- The multiple, routine challenges confronting district health systems not only include drug stock outs and funding constraints, but also unpredictable staff, patient complaints, rigid compliance demands embedded within vertical accountability processes and an array of frequently changing, and sometimes unclear, policy imperatives.

- Stable governance structures and adequate resources are not sufficient by themselves to sustain the everyday resilience of district health systems.

- Everyday resilience requires new forms of leadership that embody respect and empower others, particularly front-line health staff, as well as social networks and relationships across, within and outside the health system. Resilience is not a function of what a system has but of what it does and how it does it.

\section{Recommendations for policy}

- Governments and donors must pay greater attention to strengthening leadership across systems - the leadership that is offered collectively by multiple actors working at different levels and spaces, and that empowers others and enables learning.

- New forms of collaboration between researchers and health managers may nurture everyday resilience when researchers become embedded within the social networks surrounding and supporting health systems.

lenses to deepen our inquiry into the nature of everyday resilience. By comparing experience across settings in these analyses, we aim to reveal patterns and insights that can stimulate reflection in other settings, rather than to identify specific policy interventions for application across settings. Indeed, ultimately we suggest that these experiences show that there are no magic bullets for system strengthening; instead, developing learning processes and nurturing learning is a critical element of health system strengthening. ${ }^{78}$

\section{METHODS: LEARNING SITE SETTINGS AND OUR ANALYTIC APPROACH}

The three learning sites are embedded in two different national contexts and three, quite different local settings. In Kenya, we work in Kilifi County, one of the 47 counties established within newly devolved national governance structures in 2013; and in South Africa, in two health districts located in different provinces (Sedibeng, Gauteng; and the Mitchell's Plain area of the Metro District Health System/City of Cape Town,
Western Cape*). We have worked in Mitchell's Plain since 2010, in Kilifi, since 2012 and in Sedibeng, since 2014. These sites were chosen because prior experience and engagement with managers provided a foundation for longer-term collaboration. Sustained engagement was then made possible as research teams live locally and have maintained trusting relationships with health system colleagues over time. ${ }^{9}$

Kilifi is a rural setting compared with the urban contexts of the South African sites; and Mitchell's Plain is a subdistrict rather than a district, with a population (around 500000 people) about half that of the other sites. In Kilifi, the population is relatively poor in national terms (just over $70 \%$ live below the national poverty line); but the nominal health expenditure per head (2012$\$ 17)$ was almost similar to the national average and since devolution the county government has prioritised the health system in its budgetary allocations. However, the Kilifi health expenditure level is lower than in the South African sites (2014/2015—\$57 Mitchell's Plain, $\$ 100$ Sedibeng). Mitchell's Plain also has a lower health expenditure per head than the wider district in which it is located $(\$ 87)$, the national average $(\$ 80)$, as well as Sedibeng, where the expenditure level is above the national average. Finally, outpatient utilisation is roughly similar across sites (around 2.6-3.0 visits per head) and the antenatal care utilisation figures show what might be called reasonable performance in all sites, if with clear room for improvement. Further contextual details for each learning site are provided in the online supplementary annex.

In each site, our overall study design is flexible ${ }^{10}$; we have worked alongside managerial colleagues over time in implementing deliberate cycles of reflection-actionlearning better to understand management challenges, processes and practices across the district health system. Following other work on organisational change,${ }^{11}$ our methods of data collection include document reviews, in-depth interviews, group discussions, as well as observations; presenting and discussing 'findings' with managers (to test them and consider what managerial implications they have) and reflective discussions within the research teams. Our data, therefore, include an array of reflective notes and journal data, presentations to managers, notes from feedback meetings and transcripts of our own reflective discussions. As our approach is one of embedded health policy and systems research (HPSR), ${ }^{12}{ }^{13}$ we have sought to gather information and make sense of it with our colleagues, thereby co-producing knowledge-as discussed in more detail in a companion paper. ${ }^{14}$ In Mitchell's Plain, we have also offered support for managerial interventions initiated by our colleagues $\dagger$, and in each country we have sought to share our insights with higher-level managers where possible. These collaborations have provided the foundation for a range of interlinked analyses. ${ }^{15-18}$ For each site, ethical approval was obtained from relevant national authorities and also from the London School of Hygiene and Tropical Medicine. 
In conducting the analysis for this paper, we followed principles adapted from case study research methodology $^{19}$ and meta-synthesis. ${ }^{20}$ Within this process, identification of the routine challenges faced at district level was largely an inductive process, based on each learning site team's interpretation of experience. Our examination of resilience was, however, both inductive and deductive. We, first, collectively read and reflected on resilience, then examined our data (both already published work and additional primary data) and, finally, based on comparative analysis of experience across sites, developed an initial line of argument. A core team then prepared successive, draft manuscripts; and review, revision and paper finalisation involved further reflection among the cross-site authorship team. The cycles of reflection and multiple levels of triangulation achieved through this process underpin the trustworthiness of the resulting analysis. ${ }^{21}$ However, our inquiry into everyday resilience is inevitably exploratory given that we did not deliberately set out to examine this dimension of district health systems.

The two resilience frameworks used in our analysis allow us to understand resilience as combining strategies and capacities.

Drawing from work on vulnerability reduction programmes, ${ }^{22}$ we, first, consider the combination of absorptive, adaptive and transformative strategies that might be adopted in responding to strainł. Actors and systems exercise a combination of these strategies in response, partly, to the nature and scale of challenges experienced. Absorptive strategies seek to neutralise low-intensity or transient challenges, and return the system to its previous state with minimal or no effect on its functionality. In a PHC facility, occasional staff absenteeism can be addressed by temporary staff re-deployments within the facility by its manager, for example. However, challenges that are of a higher intensity are likely to exhaust the system's absorptive strategy, requiring it to make some limited adjustments in order to continue to function (an adaptive strategy). Persistent absenteeism by one staff member might lead to disciplinary action or moving the staff member to a different facility. However, if the shocks to the system are greater and persist, they may require the system to transform into an entirely new state through significant functional and structural changes (a transformative strategy). Persistent absenteeism by many staff might require the facility manager to be moved or a group of staff to be disciplined and moved, for example.

But what enables actors and systems to adopt relevant strategies? In addressing this question, we consider three sets of latent capacities ${ }^{3}$ that enable organisations to problem-solve (cognitive capacities), generate a store of possible actions to draw on in response to future challenges (behavioural capacities) and access resources to respond to uncertain and surprising conditions (contextual capacities) ${ }^{23}$

1. Cognitive capacities include the shared values that influence the practice of power and the development of trust, ${ }^{823}$ as well as deliberate use of language and symbols to build shared meanings and decisiveness despite uncertainty. ${ }^{23}$

2. Behavioural capacities include an organisational acceptance of risk, treating strain as an opportunity not a crisis and the belief that the organisation will cope, due in part to past experience of positive adjustment in response to challenge ${ }^{2}$; creativity, ingenuity, useful routine processes and practices that provide the first response to unexpected challenge, or that encourage employees to speak up about failures, question assumptions and learn from errors, are other capacities. $^{23}$

3. Contextual capacities comprise a willingness to take personal risks, social capital built on respectful interactions within the organisation and diffused power within the organisation and resource networks outside it. ${ }^{23}$

\section{FINDINGS}

\section{The challenging conditions faced by district health systems}

Across sites we identified three common sets of challenging conditions, with variation in the specific experience of each site, as described below.

\section{Unstable and evolving governance structures}

In Kenya, considerable political, legislative and administrative decision-making power across sectors was devolved to 47 county governments within a 6-month time frame following the election of a new government in March 2013; a process representing the adoption of a new constitution agreed in 2010. This radical and speedy devolution of power represented a major break with the political and public management traditions of the country and was a response to persistent ethnic and regional tensions over control of resources and political power. In the health sector, county officials are now responsible for medical services, public health and $\mathrm{PHC} /$ promotion, with the national level responsible for health policy formulation and regulation functions, and national referral hospitals. The first Kilifi County Director of Health moved quickly to appoint a County Health Management Team to lead and support health services, and also absorbed the previous District Health Management Teams as Sub-County Health Management Teams (SCHMTs) responsible for managing PHC service delivery. However, wider policy confusion meant that these mid-level managers were initially uncertain whether they would retain their jobs and lacked guidance on their roles and responsibilities. For example, they were unclear if they remained responsible for supervision as the new Public Finance Management Law removed their access to the funding for it.

In South Africa, a similar form of decentralisation was instituted following the 1994 election of the first postapartheid government. Provincial governments are now responsible for the provision of all health services; 
local governments, for a package of 'municipal PHC services'; and national government, for developing overarching health policy and health legislation, and support for specified prevention and disease control services. The District Health System has consistently been seen as the critical platform for strengthening $\mathrm{PHC},{ }^{24}$ but uncertainty about provincial and local government roles has, as in Kenya, provided an unstable context for PHC. In large urban centres, PHC service delivery continues to be split between provincial and local government authorities. ${ }^{25}$

In Cape Town, the provincial government only established the Metro District Health System as a functional structure in 2010 (just before we began work). Subsequent quite rapid decentralisation of decision-making authority to this structure has been accompanied by the implementation of a range of new planning and management processes that aim both to provide guidance for district managers and hold them accountable. Absorbing multiple new managerial directives, while being held responsible for service delivery targets set at higher levels and managing tensions with local government colleagues, has been challenging, especially given continuing discussions about the provincial takeover of responsibility for all $\mathrm{PHC} .{ }^{26}$

The process of devolving authority from provincial to district level has been even less straightforward in Sedibeng, established as a municipality in 2000. While the district staffing structure is well established, changes in the balance of responsibility between provincial and district managers for human resource management and procurement have caused confusion at district level, and subdistrict positions took time to fill. As a result, 'the supervision of the facilities is not ideal' and there are '... a lot of delays in the procurement processes which really has a negative impact on the functioning of the sub-district' (Sedibeng mid-level manager 1, 2014). Around 70\% of PHC clinics, meanwhile, remain under local government authority, although a significant portion of their funding comes from the provincial government. As clinic managers employed by local government are not accountable to the provincially employed District Managers, 'even when their facility is not performing, sometimes it becomes so difficult to say "how can we help" (Sedibeng mid-level manager 12, 2015).

\section{Resource challenges and frequent policy change}

Kenyan County hospitals receive the majority of their resources (in the form of staff and medical supplies) from central government and have generally been underfunded. ${ }^{27}$ However, this situation worsened after devolution as they no longer received an operations and maintenance cash budget from the centre, nor had access to locally generated fee revenue (given a June 2013 national policy decision to remove fees). PHC facilities, similarly, lost access to the newly introduced, donor-supported Health Sector Services Fund ${ }^{28}$ as well as user fee revenue: ' $[\mathrm{a}]$ series of crises resulted at facilities, including accumulation of water and electricity bills... inability to pay casual workers, and community members demanding free services that were not available'. ${ }^{18} \mathrm{New}$ procurement systems introduced post-devolution (mid 2013) then generated drug shortages, and there were delays in salary payments when human resource management was devolved to county level. The salary problems continued into 2014, demoralising staff already anxious that ethnic tensions might lead them to lose their jobs. ${ }^{18}$

Even in South Africa, resource constraints have bedevilled those working in the newly decentralised structures of Sedibeng. Observational work showed that limited access to laptops and computers affects routine activities. For example, poor internet access disrupts weak and slow procurement processes, exacerbating the usual practices of late ordering and late payment that, in turn, deter suppliers from doing business with government. Although located in one of the richest provinces, the resource constraints facing this district are primarily due to poor financial management across the province (resulting in the provincial health department being co-managed by the provincial treasury in 2014-2015).

PHC staff across South Africa have, meanwhile, experienced multiple waves of centrally directed reforms since $1994 .^{25}$ Although often seen at local level as having positive potential, these reforms have imposed huge demands on staff and managers-especially due to the "commandand-control' approach to policy implementation. ${ }^{29}$ New policies imposed without additional resources are specifically criticised as 'unfunded mandates': 'Again in $H R$, when we look for HR approval, they kept on saying they don't have money, and the service, irrespective of no money, no personnel, the MEC the president wants that thing to be implemented with immediate effect' (Sedibeng senior manager 3, 2014). Not surprisingly, health workers across the country have complained of 'transformation fatigue'. 2930

\section{Instability at the service delivery front line}

Located within the communities they serve, PHC facilities and district hospitals are the face of the health system. Staff working at this level confront the changing pattern of disease in communities, population expectations and the daily demands of patients seeking care. A single patient complaint can even escalate, with media attention, to become a political event, putting even more pressure on managers, who often lack confidence in themselves and the wider health system. ${ }^{26}$

At the same time, the vast majority of South African managerial time at both facility and subdistrict level is taken up by human resource management issues (figure 1; see also ref. ${ }^{18}$ ). For nurses, managing those with greater professional power, be they doctors or pharmacists, is particularly difficult. ${ }^{31}$ Some managers also hold quite autocratic attitudes towards those of lesser power, including patients, and this can exacerbate the challenges. ${ }^{17}{ }^{26}$ The bureaucratic procedures for disciplining staff are, meanwhile, lengthy and emotionally demanding, with outcomes uncertain. ${ }^{26} 31$ Trade Unions' participation in these processes can heighten tensions: 'They do not know their role - they are stepping over managerial issues .... They make a small issue a matter to protest about' (Sedibeng reflection meeting notes, R1, 2015). 
'In one facility, two nurses were absent, one was on sick leave and the other went for training. The manager called the remaining three nurses and explained the situation for them to share the day's tasks accordingly. One professional nurse who was allocated for maternal and child health services did not like how the tasks were divided amongst themselves. She just took her handbag, started shouting and she left the clinic. She did not report on duty for three days and was not picking up her phone. She underwent a disciplinary hearing when she reported back on duty.

(FM03)'

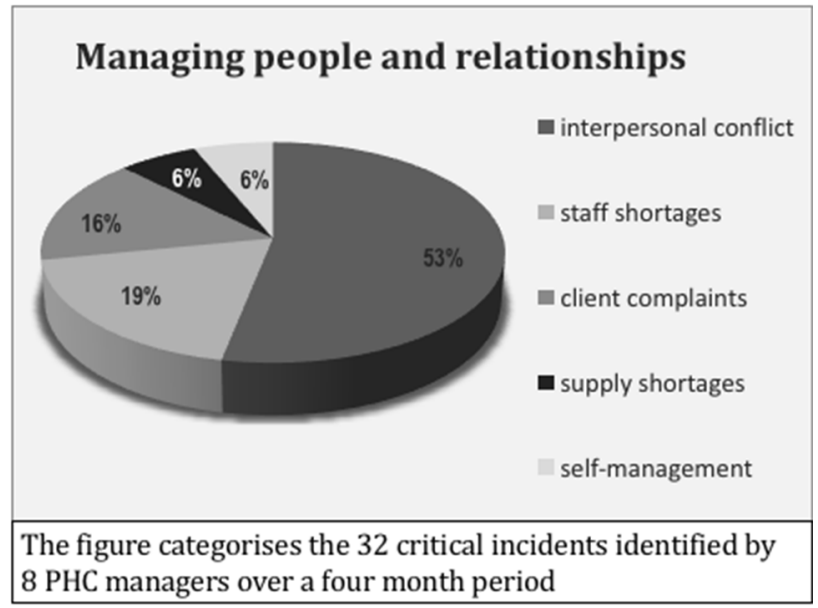

Figure 1 PHC facility managers' routine challenges, Mitchell's Plain ${ }^{31}$.

Other routine demands on managers include reporting and meetings. In Kenyan PHC facilities for example, there are nearly 50 sets of reporting forms and manuals related to clinical performance and financial management. This reporting "was variously described as "overwhelming", "repetitious" "confusing", "tedious" and "distracting" by managers and required them to work on weekends or past official hours to complete reports, particularly at month and quarter ends when reports are due in ${ }^{18}{ }^{32}$; yet they rarely received feedback. Figure 2 meanwhile presents the multiple formal and ad hoc meetings attended by seven district managers in Sedibeng, addressing both

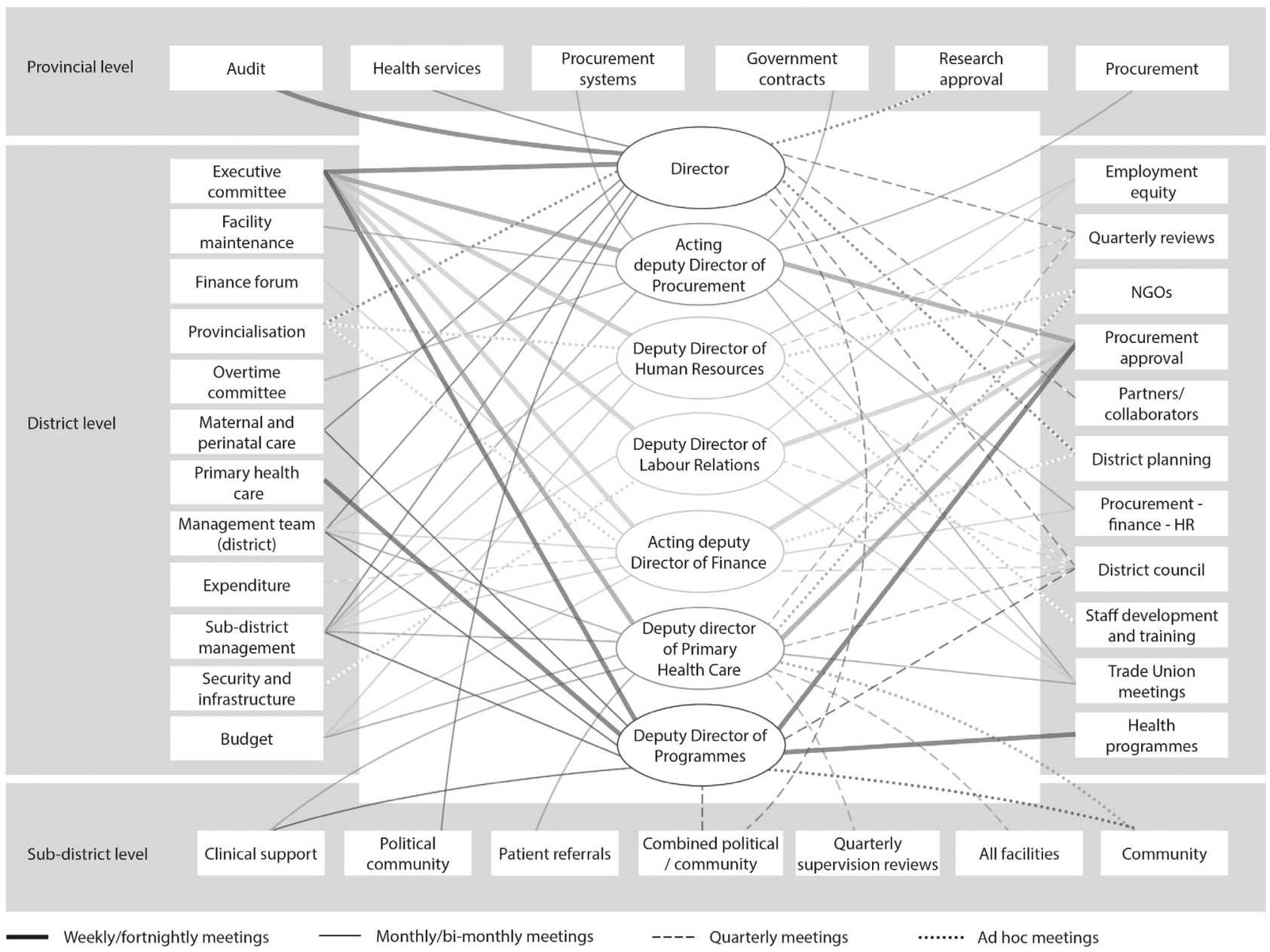

Figure 2 Routine meetings, Sedibeng District. HR, human resource; NGOs, non-governmental organisations. 
Box 1 Budget priority setting in one Kenyan district hospital ${ }^{15} 1627$

The medical superintendent had a clear interest in leadership and was highly motivated and committed:

We have a good medical superintendent. $\mathrm{XX}$ is very dedicated. And $\mathrm{XX}$ is also very helpful. $\mathrm{XX}$ is always around to attend to issues and also for us to talk [with] if we have a problem in our departments. (Middle-level manager)

In the absence of clear guidelines and procedures for priority setting, the superintendent proactively adopted an inclusive and deliberative processactively seeking out and inviting a diverse range of hospital staff to participate (including senior and middle-level managers as well as front-line clinicians). During the meetings, the superintendent sought to manage power relations by ensuring that all actors participated.

We try to make sure that all managers are involved in the budgeting process. If the budget is developed by the HMT, then every manager gets a chance to contribute. This way they understand how difficult it is to develop the budget and they understand why they cannot always get what they ask for. (Medical superintendent)

The inclusivity of the process built trust and helped develop a shared commitment among staff to deliver healthcare despite the challenges. Frontline staff reported using their own resources to buy medicines and other essential supplies for patients. Managers reported trying innovative ways to generate revenue for the hospital, such as an initiative to grow and sell sunflower seeds to cooking oil manufacturing companies to generate revenue.

\section{Box 2 Strengthening the HIV/AIDS/sexually transmitted infections/tuberculosis (HAST) programme, Mitchell's Plain ${ }^{46}$}

\section{Background}

Provincial and local government employ HAST programme staff who are jointly responsible for providing technical support to the staff and managers of primary care facilities and community-based organisations where these services are provided; and for liaising with subdistrict finance, procurement and health information system staff.

The creation of a new provincial government managerial post led to conflict between staff in the two authorities, and the research team was requested to assist in resolving it.

\section{Addressing the conflict}

The researchers facilitated a series of cross-organisational reflective discussions.

It became clear that the organisations shared a strong client-focused orientation, but that staff did not understand each other's structures and processes. Review of their two organograms showed that differences in lines of authority, acceptable lines of communication and policy implementation pathways had caused problems in communication and decision-making.

Initially, HAST managers called for a set of standard operating procedures, approved by higher-level managers, to provide instructions on how to work together.

However, further reflection highlighted the critical importance of relationships to the HAST team's work and the managers decided that a fixed agreement would not resolve existing problems. Instead they decided a framework was needed to support communication and relationships across organisations. Through a participatory workshop, HAST staff developed a set of principles for future engagement: participation for all, respectful communication, information sharing, collaboration, problem-solving, acknowledging organisational differences, passion and commitment in team work, and persistence.

\section{Lasting impacts}

Eight months after the last intervention workshop, a further cycle of reflection with HAST managers showed continued collaboration across organisations - in planning a joint campaign, supporting training and giving direct technical support to facilities.

The task team also noted that 'working together [in HAST] had spilled over into other areas' and allowed for greater collaboration between the two organisations (reflective task team meeting, 16 April 2013).

\section{Transforming ways of functioning: enabling factors}

In focusing on the principles for future engagement, the HAST managers reframed the conflict as a misalignment in organisational structures, rather than individual issues of personality and power.

This new framing made it possible for the HAST staff to be more open and trusting of their colleagues in the other organisation, and to enter a meaningful dialogue about how to work together. Having previously understood their work to be mainly technical, they also came to acknowledge that it required good relationships and that they needed relationship skills to accomplish work successfully.

The HAST managers then provided spaces in which to develop these relationships through workshops in which all staff participated to develop shared understandings of job descriptions and organograms, and negotiated a set of principles for communication and collaborative work outside the workshops. The managers also role-modelled the values underpinning collaboration by using respectful and participatory methods of problem-solving during the workshops. 
service delivery and transversal managerial issues. Overall, managers feel they spend too much time in meetings which do not have clear objectives, leaving little time for service delivery support: 'I find it difficult because most of the time it's meetings and I don't get a chance to do those operational things' (Sedibeng senior manager 4, 2014). Managerial practices and processes are also themselves rooted in broader organisational cultures: the South African public health system, for example, is commonly experienced as rigid, top heavy and isolating. ${ }^{33}$

Despite these demands, across countries PHC facility managers (and even hospital managers ${ }^{27}$ ) are appointed with very little preparation or relevant training. Kilifi PHC facility managers "remembered how "unprepared" they were to manage facilities on their first posting, and how "shocked " or "overwhelmed" they were by the breadth of their roles' ${ }^{18}$ Similarly, in Mitchell's Plain '... no one tells you how to be [a PHC facility] manager and instead you learn to be one by doing the job'. ${ }^{31}$ Commonly, therefore, facility managers focus on their clinical role, where they feel confident, rather than proactively addressing problems, ${ }^{1726}$ and neglect other important managerial activities-such as engaging staff in important decisions ${ }^{27}$ or encouraging wider community engagement. ${ }^{31}$

\section{System responses to challenging conditions}

The responses to these challenges that we identified were implemented by managers based at different levels within the district health system and varied across learning sites and even between facilities.

In Kenya, the subcounty managers played a critical role in supporting PHC facility managers to keep services operating in the uncertainty of the immediate postdevolution period-demonstrating huge commitment to their staff. As one manager said, 'These are my nurses, my doctors, my people (the community), so I cannot let them down, we have to help each other'. Some defended PHC facility managers from criticism by newly appointed Members of the County Assembly, ${ }^{18}$ and they were themselves supported, and encouraged, by one of the senior county health managers who delayed implementation of a Ministry of Health directive to downsize SCHMTs. SCHMT members also sometimes used their own resources to continue supervision, as well as leveraging resources through their relationships with vertical programme managers whose funding was not devolved to county level. At the same time, they adapted their routine activities to fit with the new realities. For example, as they were not able to continue with supervision visits to all facilities, the SCHMT made greater use of their monthly meetings with groups of managers to review progress and discuss how to address challenges. ${ }^{18}$ Follow-up supervision visits were then made to the least well-performing facilities. Finally, the SCHMT in one subdistrict contained a cholera outbreak in 2014, by mobilising resources from a local non-governmental organisation (NGO) to support their travel to the affected area, to collect samples and send them to the national level for analysis, and to transport suspected infected patients to the nearest hospital for treatment\$.

Facility managers, meanwhile, adopted various strategies to cope with resource constraints. A very proactive strategy was employed by one PHC facility level, who worked with clinic committee members to address the funding crisis-by agreeing to reintroduce user fees locally until the government released funding. The clinic committee then supported the PHC manager against the county managers' criticism of this decision. Fees were subsequently reintroduced on a temporary basis across the county to ensure continued service provision. ${ }^{18}$ In district hospitals, meanwhile, hard budget choices had to be made to support continued service delivery given the funding challenges. Barasa $e t a l^{151627}$ report experiences from two hospitals. In one (box 1), a dedicated leader adopted inclusive and deliberative decision-making processes-generating wide-ranging staff commitment to the budget priorities set collectively and strengthening the collective sense of staff duty to the hospital and its patients. In the other, the budgeting process was dominated by a few senior managers-resulting in tensions with other staff, who felt budget decision-making was unfair. Ultimately, however, both hospitals responded to resource constraints by prioritising departments and services that had the greatest potential to generate fee revenue for the hospital. This led to the systematic underfunding of other departments such as paediatrics and physiotherapy, undermining staff morale and their quality of care.

Sedibeng managers have also coped with front-line resource challenges by sometimes accommodating unacceptable circumstances in ways that might have negative consequences for service delivery. For example, a provincial moratorium on new staff appointments led to staff being appointed to positions for which they are not fully qualified, and new activities being implemented without dedicated staff. 'We have 170 people that are in the wrong post... for example, a person occupies a post, for instance a dietician, but that person is actually a nurse. That negatively affects things. This happens because the service must be delivered, or there is an unfunded mandate, and you need to find a post, and so a person would land up in the wrong post' (senior manager $11,2015)$.

At the same time, a strong budget submission by the district manager to provincial authorities in 2014 secured new resources to hire additional nurses to supervise community health worker (CHW) teams working at household level (initially 39 teams, rising to 44 by 2016 , in half the district's wards).

In Mitchell's Plain, meanwhile, various initiatives have been taken by subdistrict managers to strengthen their support for front-line health staff and service delivery in response to the routine challenges, some implemented with the learning site research team. These include engaging facility staff and environmental health practitioners in mapping local health resources and needs with community actors, and working together to address local 
problems; encouraging facility managers and their staff to develop locally specific priorities for their work; adapting the processes of routine meetings to encourage greater reflection and more proactive problem-solving through collaboration across managerial levels; and deliberate role-modelling of inclusive managerial practices by more senior managers, through respectful behaviour and language. ${ }^{172634}$ Success has varied, and maintaining new managerial practices in the face of continuing challenge is hard work; but all indicate the subdistrict managers' efforts to develop a new organisational culture of collective inquiry and mutual accountability. ${ }^{17}$ Hints of the potential gains from these practices include the novel outreach strategies to extend immunisation coverage and family planning service improvements implemented by some PHC facility managers ${ }^{35}$; and the persistence of environmental health practitioners in engaging community members and other sectors to address a range of community health challenges. ${ }^{34}$

A final example from Mitchell's Plain also provides ideas about how new approaches to tackling common challenges might be developed. Faced with tensions between local and provincial government staff working in the HIV/AIDS/sexually transmitted infections/tuberculosis (HAST) programme, subdistrict managers approached the research team for support (box 2). The initial request was to establish clear roles and responsibilities for the various members of the HAST team. However, after discussion, the HAST team decided that an effective working relationship would be better supported by improved communication across the organisational boundaries. They developed a set of principles to guide their collaboration that would also allow roles and responsibilities to evolve organically over time, in response to changing needs. These principles underpinned continuing collaboration in the HAST programme and supported the emergence of wider collaboration between the organisations.

\section{DISCUSSION}

Our findings illuminate, first, the challenging conditions that are the norm for those working in district health systems in low-income and middle-income countries. Health managers at these levels routinely face instability, such as changes in governance structures and financing mechanisms, payment and other resource provision delays, and frequent, abruptly imposed policy directives. They commonly work with unstable authority delegations, manage unpredictable staff and address changing patient and community expectations. These conditions are not the acute, external shocks more usually discussed in relation to health system resilience. ${ }^{1}$ Instead they are internally generated chronic stresses, some of which are even infused into the routine organisational life of health systems (as in the case of centralised, command and control management practices). The stresses occur at the same time in the same system, impacting on the same set of people-and they interact, for example, unstable organisational structures or resource challenges generate tensions in relationships with staff or the community, with possible consequences for service delivery. Change is, therefore, pervasive in organisations-'uncertainty and surprise is part of the game and you need to be prepared for it and learn to live with it' ${ }^{36}$ This situation simply demands everyday resilience.

Second, we observed a range of managerial responses to these routine challenges. However, further analysis is required to judge whether they indicate or nurture everyday resilience. Table 1 categorises these responses using the ideas drawn from Bene et $a t^{22}$ (summarised earlier) and presents judgements against the yardstick that resilience is seen when organisational functioning is strengthened. ${ }^{3}$ Here, we understand this to mean that service delivery improved or was scaled up, or organisational developments that may support service delivery were sustained.

The 'resilience judgements' of the table suggest that the experiences were mixed, with only some suggesting resilience. In several instances, absorptive or adaptive strategies seemed to represent undesirable or unsustainable organisational practices, termed 'maladapted emergence' in the literature on complex adaptive systems. ${ }^{32}$ The reintroduction of user fees in Kilifi to cope with funding shortfalls, despite a prior policy decision to remove them because they reduce access for the poorest, is one example; a second is the appointment of staff to posts for which they were not qualified or the implementation of new activities without dedicated staff in Sedibeng. Even within strategies that appear more likely to reflect everyday resilience, there may be weak spots; for example, Kilifi mid-level managers using their own funding for their work is not sustainable; and strengthened organisational practice in one Kilifi hospital was nonetheless accompanied by a decision that had negative consequences for service delivery (box 1).

Table 1 also offers some insight into the types and combinations of managerial strategies that might underpin resilience. Although individual managers' exercise of agency and discretionary power ${ }^{22}$ was commonly important, these experiences seem to suggest that individual action to absorb or moderate disruption does not itself demonstrate everyday resilience at system level. Instead it must be incorporated within other strategies; for example, becoming an adaptive strategy that promotes organisational resilience, as with the Kilifi County manager's support for the SCHMT or Sedibeng's CHW programme development. Indeed, adaptive and transformative strategies appear to entail working with others, within and across levels of the health system. The transformative strategies identified for Kilifi and Mitchell's Plain also point tentatively to the importance of new managerial routines and practices in more substantial renewal, reorganisation and development-such as establishing principles for decision-making that can 

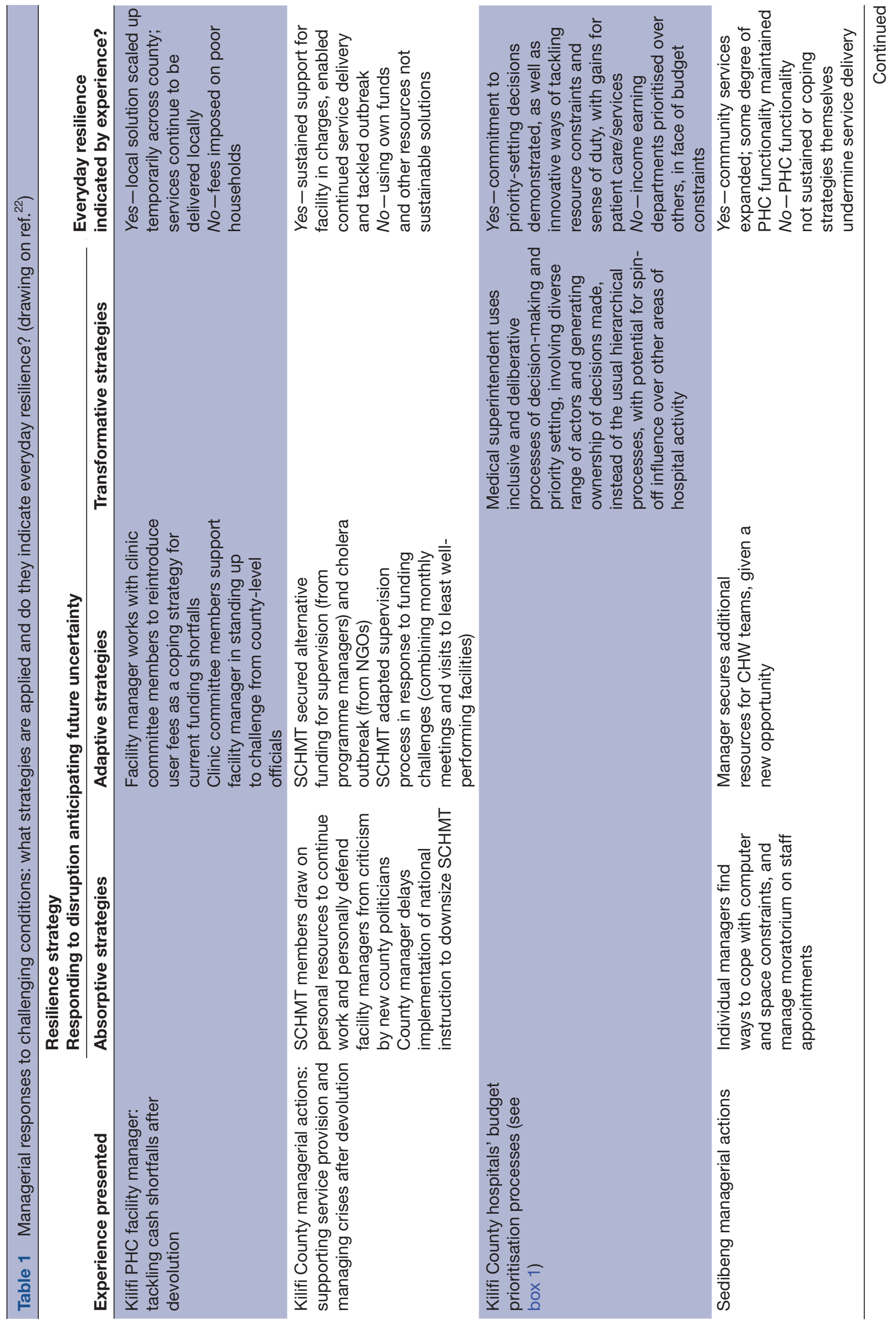

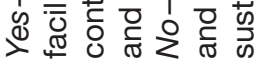

\&

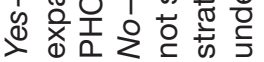
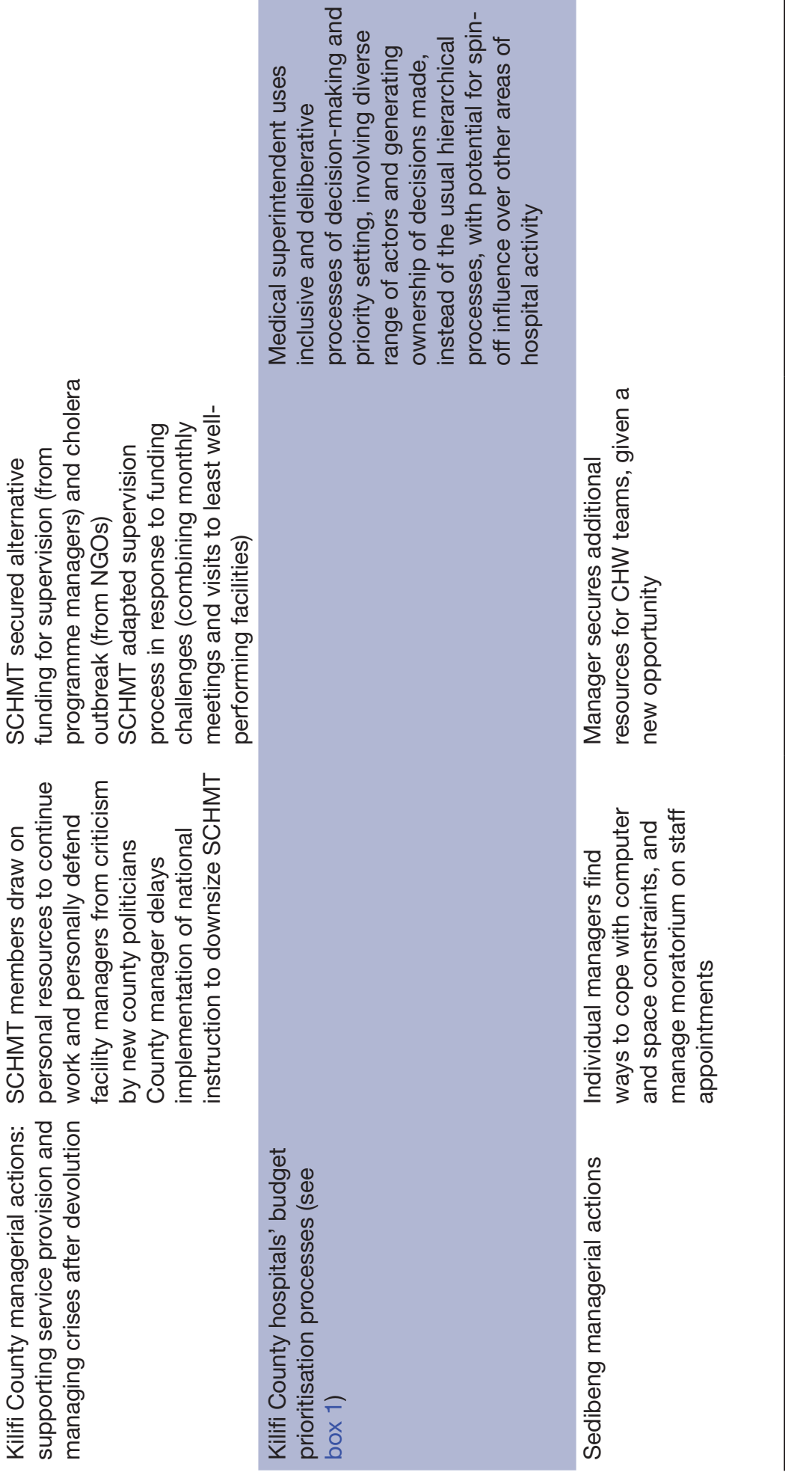

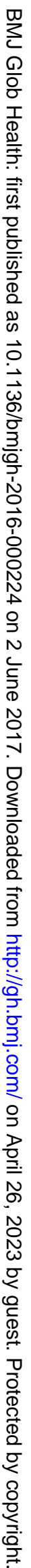




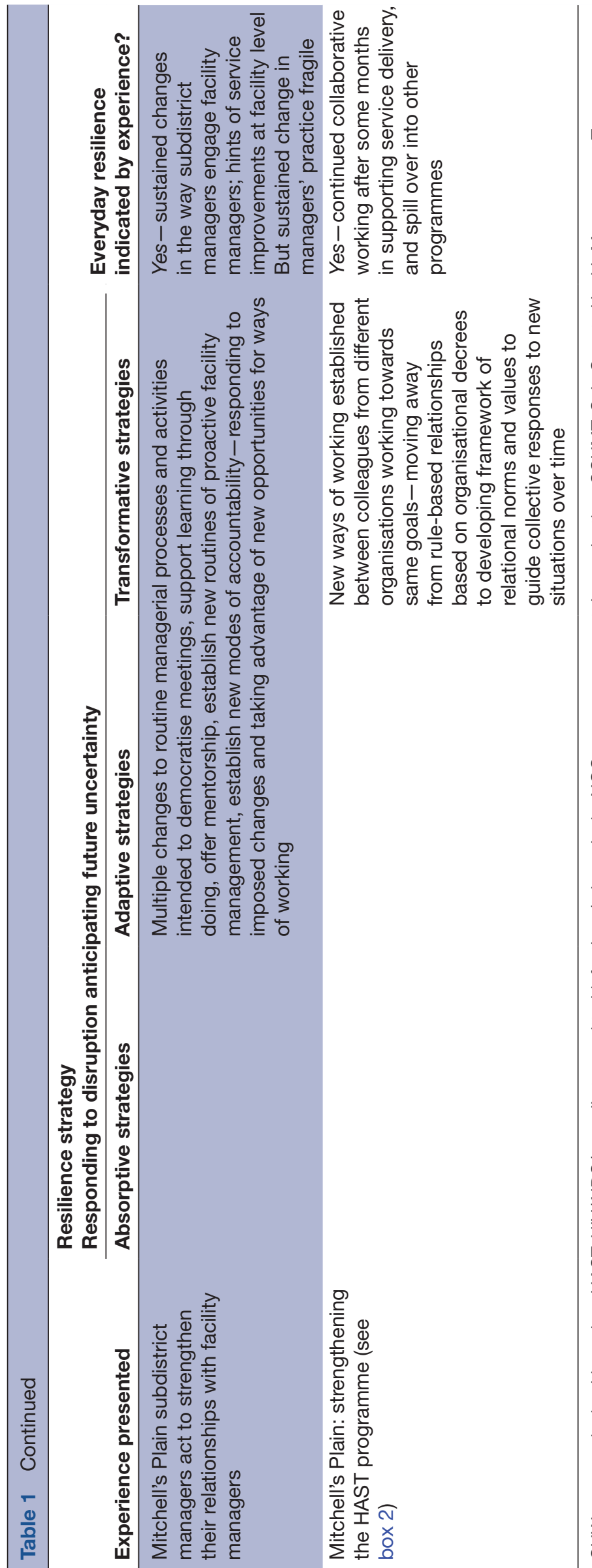

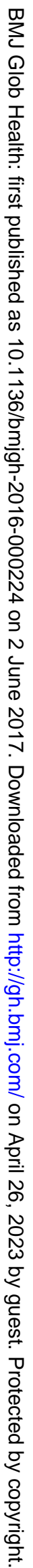


guide collective responses to new challenges as they emerge over time. ${ }^{366}$

Table 2, then, considers further the organisational capacities underpinning adaptive and transformative strategies. In Kilifi, for example, individual SCHMT managers demonstrated a sense of purpose, decisiveness and concern for others (cognitive resources) and learnt ingenuity (a behavioural resource) in adapting supervision practices given the challenges experienced; and they drew on their social networks with vertical programme managers/NGOs (contextual, relational resources) to secure funding to support PHC facility managers/ respond to the cholera outbreak. In Mitchell's Plain, meanwhile, the HAST programme experience (box 2) shows how a new behavioural resource, the potential for future collaborative responses to new challenges, was enabled. New principles to guide communication and engagement practices (useful, practical habits; a behavioural resource) were established through a participatory process involving front-line staff (drawing on diffused power; a contextual factor), in which managers demonstrated a sense of purpose and decisiveness, role-modelled respectful behaviours and, through their language, supported new understandings to emerge (cognitive resources). This last example also indicates the possibility that capacities for resilience may be developed through responses to challenges.

Together these analyses provide three initial, overarching insights about everyday resilience-each of which is confirmed by other empirical literature and related theory.

First, the analyses indicate that individual agency does not by itself underpin everyday resilience. Rather, it must enable or be incorporated within adaptive and transformative strategies to nurture organisational resilience. Individual and organisational capacities are, therefore, interconnected: 'an organisation's capacity for resilience is embedded in a set of individual level knowledge, skills, and abilities and organisational routines and processes by which a firm conceptually orients itself, acts decisively to move forward, and establishes a setting of diversity and adjustable integration' that enables it to overcome challenge. $^{23}$

Second, relationships and social networks within the health system underpin everyday resilience. ${ }^{2332}{ }^{36}$ In adaptive and transformative strategies, for example, managers acted to strengthen relationships with their staff or staff in other organisations, or to establish new practices that allow relationship building (eg, Kilifi hospital, box 1; Mitchell's Plain, HAST intervention, box 2); and/or drew on existing relationships to achieve broader effects (eg, Kilifi SCHMT drew on their relationships with vertical programme managers in leveraging resources). Wider empirical evidence and theory suggests that social networks, including with communities, provide access to the multiple resources and forms of value (material, knowledge, reputational) that support sustained and transformed organisational functionality. ${ }^{1} 23236-38$
Unusually, our experience offers specific insights about how collaboration between researchers and health managers might nurture everyday resilience. We have sought to accompany PHC-level health system change through cycles of reflection and learning with our managerial colleagues (box 3) and sometimes supported their managerial initiatives. In addition, we have shared this front-line experience with higher-level managers. In Kilifi, for example, the research team's wider engagement has led to the national development of stronger planning and budgeting processes for the new devolved environment, as well as county-level action to tackle the funding crises. In Mitchell's Plain, meanwhile, the research team has drawn from its experience in developing a leadership competency framework and leadership development strategy for the provincial government. In various ways, therefore, the research teams have become part of the social network in the learning sites, offering local managers access to wider sets of resources.

Third, the experiences highlight the particular importance of leadership to everyday resilience, exercised by managers throughout the district health system. Leadership entails enabling others to face challenges and achieve results under complex conditions, ${ }^{3940}$ and as shown here, is likely based on values such as respect for others, or a sense of duty, is inclusive, empowering others to be decisive and innovative in response to challenge, and entails role-modelling, and the deliberate use of language to encourage new ways of seeing problems and opportunities. Importantly, this form of leadership provides an enabling environment for the front-line managers and health staff whose confidence, commitment and motivation are essential in resilient health systems. ${ }^{16} 173741$ Indeed, theory notes that 'the behavioural processes of mindful organising engaged by front line employees' are critical for resilience, ${ }^{3}$ not least because they generate the learning, innovation and new organisational routines that absorb and adapt in response to future challenge-and transform further, as needed. ${ }^{8} 233642$ The leadership that sustains everyday resilience is, therefore, adaptive ${ }^{42}$ and distributed ${ }^{43}$ - that is, it is exercised by managers across the system (rather than only by higher-level managers) who sometimes function as leaders and sometimes as followers in interlinking chains of teams, and who collectively influence others in responding and adapting to challenge.

A fourth and final point derived from the experiences reported here but not clearly highlighted in table 1 or 2 is that material resources (eg, funding and staff levels) and organisational structures influence resilience. This is seen most clearly in Kilifi and Sedibeng, where challenging processes of decentralisation occurring against a background of resource constraints have generated role confusion and encouraged coping and adaptive strategies with undesirable or unsustainable consequences (see also ref. ${ }^{6}$ ). In such settings, resources and organisational stability (organisational hardware) are, clearly, important to health system resilience. Yet even here, the organisational software ${ }^{44}$ of new forms 


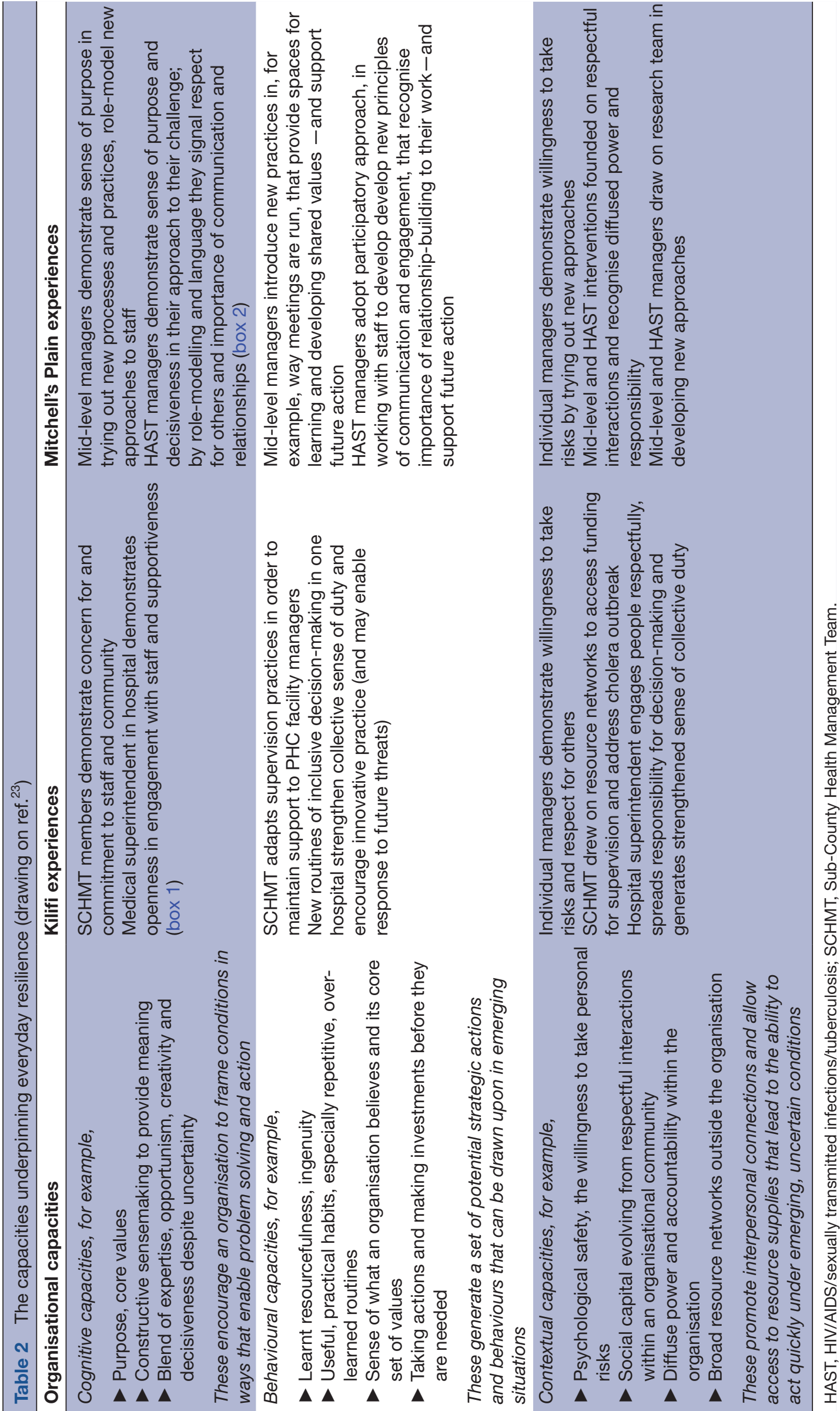


of leadership and relationships are vital in supporting the emergence of strengthened ways of working (box 1; also refs. ${ }^{151618}$ ).

\section{CONCLUSIONS}

We have both confirmed the relevance of the concept of everyday resilience by illuminating the routine and chronic challenges of PHC and district health systems, and begun to consider the types of managerial strategies and organisational capacities that generate such resilience. From our analysis, we propose that everyday resilience in district health systems is derived from forms of leadership that reframe challenges to support problem-solving; embody respect and empower others, particularly front-line managers and staff; enable learning and innovation; and draw on and catalyse social networks and relationships across, within and outside the health system. Individual agency is important to such leadership, but resilience is derived from spreading that agency to organisational level through relationships, as well as new organisational routines and resources. Stable governance structures and adequate resources may also have importance in some contexts, but are not by themselves all that is needed to generate resilience.

Health system strengthening must, therefore, pay closer attention to the software of health systems. Everyday resilience is not a function of what a system has but of what it does and how it does it, and so strengthening its capacity is '... more than simply providing assets or technology. It is about developing people's agency, it is about governance and power' ${ }^{22}$ As others have argued, strengthening governance and leadership within health systems is critical to their development and performance. ${ }^{545}$ Resilience specifically is nurtured by developing the internal organisational capacities needed to adjust to and learn from routine challenges, and preserve or even improve health system functioning. The forms and approaches of health system strengthening must guard against undermining these capacities.

\section{Box 3 Reflection on working with the research team ${ }^{34}$}

What made it work for [me] was having the support of and reflection with [DIALHS colleagues (researchers)]... I had them on my side... That is what I liked about our relationship - is that we could reflect back and say 'what went wrong here? How could we do it differently?' That is what made me continue ... because the reflection of it [the situation] was never about methe person-but about how the situation was managed. And that is what made it work for me. (Writing Reflective Workshop I, March 2015)
Further research can, finally, build on the analyses presented in this paper to generate deeper understanding of the range of strategies and underlying organisational capacities that lead to improved organisational functioning (everyday resilience), through what pathways and with what consequences for overall health system performance. Further inquiry into the potential of embedded research ${ }^{1213}$ as a resilience resource may itself be worthwhile. At the same time, the learning site experience suggests that accompanying those working within health systems over time is an important research approach for understanding the complex and long-term processes of health system change.

a. More specifically we have worked in one geographic area in which health services are managed by two different health authorities. The area is the Mitchell's Plain subdistrict of the City of Cape Town, a local government authority, which falls within the Mitchell's Plain/Klipfontein substructure, one of four within the provincial government's Metro District Health System.

b. The learning site work in Kilifi County and Sedibeng began later and moved at a slower pace than in Mitchell's Plain, with fewer opportunities at the time of writing to support locally led changes in managerial practice.

c. Although Bene et $a l^{22}$ use the term capacities, we propose they are more usefully seen as strategies as they reflect alternative courses of action that might be taken by a system in responding to challenge.

d. The evidence in this paragraph is drawn partly from an unpublished manuscript, based on the Kilifi work: Nyikuri M, Tsofa B, Okoth P, Barasa E, Molyneux S. 'We are toothless and hanging, but optimistic': Sub county managers' experiences of rapid devolution in Coastal Kenya.

e. These insights reflect the wider experience of development practitioners, ${ }^{38}$ including those working specifically on organisational capacity development.

Correction notice This paper has been amended since it was published Online First. Owing to a scripting error, some of the publisher names in the references were replaced with 'BMJ Publishing Group'. This only affected the full text version, not the PDF. We have since corrected these errors and the correct publishers have been inserted into the references.

Acknowledgements The authors thank all those involved in all three learning site teams, both managers and researchers - and especially, Shakira Choonara, Soraya Ellokor, Salamina Hlahlane, Mary Nyikuri, Tim Malingi, Patti Olckers, Nikki Schaay and Vera Scott. The preparation of the paper benefited from discussions at an April 2016 writing workshop organised by the Consortium for Health Systems Innovation and Analysis to generate deeper Southern-led perspectives on health systems and governance issues. Lucy Gilson, Edwine Barasa, Nonhlanhla Nxumalo, Susan Cleary, Jane Goudge, Sassy Molyneux and Benjamin Tsofa are members of the Consortium for Resilient and Responsive Health Systems.

Contributors All authors were involved in conceptualising this paper and in conducting analyses for it. LG, EB and UL were responsible for initiating the drafting and revisions of this paper. NN, SC, JG, SM and BT read and commented on successive paper drafts. All authors were also involved in the underlying data collection and analysis processes in the different learning sites. LG, SC and UL work together. JG and NN work together. EB, SM and BT work together. The work that provided the foundation for this paper is continuing; data already collected remain available to the researchers only. 
Funding Funding for the work reported here was provided, in part, by Atlantic Philanthropies. In addition, this document is an output from a project funded by the UK Aid from the UK Department for International Development (DFID) for the benefit of developing countries.

Disclaimer The views expressed and information contained in the article are not necessarily those of or endorsed by DFID, which can accept no responsibility for such views or information or for any reliance placed on them.

Competing interests None declared.

Ethics approval London School of Hygiene and Tropical Medicine, University of Cape Town, University of the Witwatersrand, KEMRI, Kenya

Provenance and peer review Not commissioned; externally peer reviewed.

Open Access This is an Open Access article distributed in accordance with the Creative Commons Attribution Non Commercial (CC BY-NC 4.0) license, which permits others to distribute, remix, adapt, build upon this work non-commercially, and license their derivative works on different terms, provided the original work is properly cited and the use is non-commercial. See: http://creativecommons.org/ licenses/by-nc/4.0/

(C) Article author(s) (or their employer(s) unless otherwise stated in the text of the article) 2017. All rights reserved. No commercial use is permitted unless otherwise expressly granted.

\section{REFERENCES}

1. Kruk ME, Myers M, Varpilah ST, et al. What is a resilient health system? Lessons from Ebola. The Lancet 2015;385:1910-2.

2. Sutcliffe KM, Vogus TJ. Organizing for resilience. In: Cameron KS, Dutton JE, Quinn RE, eds. Positive organizational scholarship: foundations of a new discipline. San Francisco: Berrett-Koehler, 2003:p94-110.

3. Vogus TK, Sutcliffe KM; Organizational resilience: towards a theory and research agenda. In Systems, Man and Cybernetics, 2007. ISIC IEEE International Conference on 2007 oct 7 (pp. 3418-3422). IEEE.

4. Commission on the Social Determinants of Health. Closing the gap in a generation: health equity through action on the social determinants of health. Geneva: World Health Organisation, 2008.

5. World Health Organisation. The World Health Report 2008. primary Health Care: now More than ever. Geneva: World Health Organization, 2008.

6. Lembani M, de Pinho H, Delobelle P, et al. A case study of maternal health service provision in OR Tambo District. Eastern Cape, in the context of chronic poor health performance. Rebuild Consortium: Mailman School of Public Health, Columbia University, 2015. https:// rebuildconsortium.com/resources/research-reports/a-case-studyof-maternal-health-service-provision-in-or-tambo-district-easterncape-in-the-context-of-chronic-poor-health-performance/ (cited 24 Feb 2017).

7. Swanson RC, Atun R, Best A, et al. Strengthening health systems in low-income countries by enhancing organizational capacities and improving institutions. Global Health 2015;11:5.

8. Baser H, Morgan P. Capacity, Change and Performance Study Report. Discussion Paper No 59B. Maastricht (The Netherlands): European Centre for Development Policy Management, 2006.

9. Health System Learning Sites. understanding health systems through research and collaboration. RESYST Policy Brief http:// resyst.Ishtm.ac.uk/sites/resyst.Ishtm.ac.uk/files/docs/reseources/ Learning\%20site\%20brief.pdf (cited 22 Feb 2017).

10. Robson C. Real world research: a resource for social scientists. 3 ed. Chichester, West Sussex: John Wiley, 2013.

11. Pettigrew AM. What is a processual analysis? SJM 19971997;13:337-48;13:337-48.

12. Olivier J, Scott V, Molosiwa D, et al. Embedded systems approaches to health policy and systems research. In: de Savigny D, Blanchet K, Adam T, eds. Applied Systems thinking for Health Systems Research: a Methodological Handbook Maidenhead. Berkshire: Open University Press, 2017.

13. World Health Organization. Strategy on Health Policy and Systems Research: changing the Mindset. Geneva: World Health Organization, 2012. http://apps.who.int/iris/bitstream/10665/77942/ 1/9789241504409_eng.pdf.

14. Lehmann U, Gilson L. Researching people-centred health systems: the reward and challenge of co-production for HPSR. Health Policy and Planning 2015;30:957-63.

15. Barasa EW, Cleary S, English M, et al. The influence of power and actor relations on priority setting and resource allocation practices at the hospital level in Kenya: a case study. BMC Health Serv Res 2016;16:536

16. Barasa EW, Cleary S, Molyneux S, et al. Setting healthcare priorities: a description and evaluation of the budgeting and planning process in county hospitals in Kenya. Health Policy Plan 2017;32:czw132. Epub ahead of print.

17. Gilson L, Elloker S, Olckers P, et al. Advancing the application of systems thinking in health: South African examples of a leadership of sensemaking for primary health care. Health Res Policy Syst 2014;12:30.

18. Nyikuri M, Tsofa B, Barasa E, et al. Crises and resilience at the frontline-public health facility managers under devolution in a SubCounty on the Kenyan Coast. PLoS One 2015;10:e0144768.

19. Yin R. Case study research: design and methods. Thousand Oaks, California: Sage, 2014.

20. Barnett-Page E, Thomas J. Methods for the synthesis of qualitative research: a critical review. BMC Med Res Methodol 2009;9:1.

21. Patton $M Q$. Enhancing the quality and credibility of qualitative analysis. Health Serv Res 1999;34(5 Pt 2):1189-208.

22. Bene C, Godfrey-Wood R, Newsham A, et al. Resilience: new Utopia or New Tyranny? reflection about the potentials and limits of the concept of resilience in relation to vulnerability reduction programmes. IDS Working Papers 2012;1:1-61.

23. Lengnick-Hall CA, Beck TE, Lengnick-Hall ML. Developing a capacity for organizational resilience through strategic human resource management. Hum Resour Manage Rev 2011;21:243-55.

24. Chopra M, Lawn JE, Sanders D, et al. Achieving the health Millennium Development Goals for South Africa: challenges and priorities. The Lancet 2009;374:1023-31.

25. Naledi T, Barron P, Schneider H. Primary Health Care in SA since 1994 and Implications of the New Vision for PHC Re-engineering. In: Padarath A, English R, eds. South African Health Review 2011. Durban: Health Systems Trust, 2011:17-28.

26. Ellokor S, Olckers P, Gilson L, et al. Crises, Routines and Innovations - the complexities and possibilities of sub-district management. In: Padarath A, English E, eds. South African Health Review 2012/3. Durban: Health Systems Trust, 2013:161-73.

27. Barasa EW, Molyneux S, English M, et al. Hospitals as complex adaptive systems: a case study of factors influencing priority setting practices at the hospital level in Kenya. Soc Sci Med 2017;174:104-12.

28. Waweru E, Goodman C, Kedenge S, et al. Tracking implementation and (un)intended consequences: a process evaluation of an innovative peripheral health facility financing mechanism in Kenya. Health Policy Plan 2016;31:137-47.

29. Local Government and Health Consortium. Decentralising health services in South Africa: constraints and opportunities - a crosscutting report. Durban: Health Systems Trust, 2004.

30. Scott V, Mathews V, Gilson L. Constraints to implementing an equitypromoting staff allocation policy: understanding mid-level managers' and nurses' perspectives affecting implementation in South Africa. Health Policy Plan 2012;27:138-46.

31. Daire J, Gilson L. Does identity shape leadership and management practice? Experiences of PHC facility managers in Cape Town, South Africa. Health Policy Plan 2014;29:ii82-ii97.

32. Marion R, Bacon J. Organizational extinction and complex Systems. Emergence 1999;1:71-96.

33. Nationalism VHK. Bureaucracy and the developmental state: the south african case. S Afr Rev Sociol 2010;41:4-27.

34. Cleary S, Schaay N, Botes E, et al. Gilson L (2015) Re-imagining community participation at the district level: Lessons from the DIALHS collaboration. In: Padarath A, King J, English R, eds. South African Health Review 2014/15. Durban: Health Systems Trust, 2015:151-62.

35. Scott V. A health system perspective on factors influencing the use of health information for decision-making in a district health system. PhD thesis. University of the Western Cape, South Africa; 2015.

36. Folke C. Resilience: the emergence of a perspective for socialecological systems analyses. Global Environmental Change 2006;16:253-67.

37. Bloom G, MacGregor H, McKenzie A, et al. Strengthening Health Systems for resilience. IDS Practice paper in brief 18: Institute for Development Studies, 2015. https://opendocs.ids.ac.uk/opendocs/ bitstream/handle/123456789/5851/ID559\%20Online\%20rev.pdf? sequence $=1$ (cited 20 Feb 2017).

38. Booth D, Unsworth S. Politically smart, locally-led development London: Overseas Development Institute, 2014. ODI discussion paper. https://www.odi.org/sites/odi.org.uk/files/odi-assets/ publications-opinion-files/9158.pdf (cited 20 Feb 2017). 
39. Galer JB, Vriesendorp S, Ellis A. Managers who lead: a handbook for improving health services. Cambridge, Mass: Management Sciences for Health, 2005.

40. Kotter JP. What leaders really do. Boston, MA: Harvard Business School, 1990.

41. Ager AK, Lembani M, Mohammed A, et al. Health service resilience in Yobe state, Nigeria in the context of the Boko Haram insurgency: a systems dynamics analysis using group model building. Confl Health 2015;9:1.

42. Uhl-Bien M, Marion R, McKelvey B. Complexity Leadership Theory: shifting leadership from the industrial age to the knowledge era. Leadersh Q 2007:18:298-318.
43. Sheikh K, Gilson L, Agyepong IA, et al. Building the field of health policy and systems research: framing the questions. PLoS Med 2011;8:e1001073.

44. de Savigny D, Adams T. Systems thinking for health systems strengthening. Geneva: WHO, 2009.

45. Alliance for Health Policy and Systems Research. Open Mindsets: participatory leadership for Health. Flagship Report 2016. Geneva: World Health Organisation, 2016.

46. Scott V, Schaay N, Olckers P, et al. Exploring the nature of governance at the level of implementation for health system strengthening: the DIALHS experience. Health Policy Plan 2014;29:ii 59-ii70. 